(6) OPEN ACCESS

\title{
Risk factors for unplanned pregnancy among young women in Tanzania
}

\author{
Clara Calvert, ${ }^{1}$ Kathy Baisley, ${ }^{2}$ Aoife M Doyle, ${ }^{3}$ Kaballa Maganja, $^{4}$ \\ John Changalucha, ${ }^{5}$ Deborah Watson-Jones, ${ }^{6}$ Richard J Hayes, ${ }^{7}$ \\ David A Ross ${ }^{8}$
}

For numbered affiliations see end of article.

\section{Correspondence to}

Miss Clara Calvert, Department of Infectious Disease Epidemiology, London School of Hygiene and Tropical Medicine, Keppel Street, London WC1E

7HT, UK;

clara.calvert@|shtm.ac.uk

Received 13 May 2012 Revised 13 May 2013 Accepted 30 May 2013 Published Online First 31 July 2013

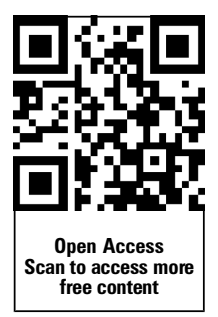

To cite: Calvert C, Baisley $\mathrm{K}$, Doyle AM, et al. J Fam Plann Reprod Health Care 2013;39: e2.

\begin{abstract}
Background With effective contraceptives available, unplanned pregnancies are preventable and educational interventions have been cited as a promising platform to increase contraceptive use through improving knowledge. However, results from trials of educational interventions have been disappointing. In order to effectively target future interventions, this study aimed to identify risk factors for unplanned pregnancy among young women in Mwanza, Tanzania.

Methods Data were analysed from the MEMA kwa Vijiana Trial Long-term Evaluation Survey, a cross-sectional study of 13814 young adults aged 15-30 years in Mwanza, Tanzania. Potential risk factors for unplanned pregnancy were grouped under three headings: sociodemographic, knowledge of and attitude towards sexual health, and sexual behaviour and contraceptive use. Conditional logistic regression was used to identify predictors of reported unplanned pregnancy among all sexually active women.
\end{abstract}

Results Increasing age, lower educational level, not being currently married, knowing where to access condoms, increasing number of sexual partners and younger reported age at sexual debut were associated with unplanned pregnancy.

Discussion A number of demographic and sexual behaviour risk factors for pregnancy are identified which will help guide future intervention programmes aiming to reduce unplanned pregnancies. This study suggests effective measures to prevent unplanned pregnancies should focus on encouraging girls to stay in school.

\section{BACKGROUND}

Worldwide, around 80 million unplanned pregnancies are estimated to occur annually. Whilst for some women an unplanned pregnancy may be welcome news, in certain situations unplanned pregnancies can lead to health, social and

\section{KEY MESSAGE POINTS}

- Unplanned pregnancy is common amongst young women in the Mwanza region of Tanzania.

- One of the key socio-demographic risk factors for unplanned pregnancy in young women is low educational level.

- Interventions for reducing unplanned pregnancy should include a component that aims to improve retention of young women in education.

economic problems. $^{2} 3$ In Tanzania, women face a 1-in-24 lifetime risk of maternal mortality. ${ }^{4}$ However, for women aged 15-24 years, the group at highest risk of having an unplanned pregnancy, the risk of maternal mortality is likely to be higher ${ }^{6}$ due in part to physical immaturity but compounded by their lack of knowledge and experience. ${ }^{7} 8$ Furthermore, in some parts of sub-Saharan Africa (SSA) pregnancies amongst single women result in stigma, and physical and mental abuse. An ethnography conducted in the Mwanza region of Tanzania found that premarital pregnancy could “reduce a woman's brideprice, create financial or legal burdens for her sexual partner, limit either partner's choices of spouse, and lead to school girl expulsion". ' In some situations, women will seek an abortion for an unplanned pregnancy which, in parts of Africa, is illegal, and consequently dangerous. ${ }^{10}$

When effective contraceptives are available and used consistently and correctly, unplanned pregnancies are preventable. Educational interventions have been cited as a promising platform to increase contraceptive use through improving 
knowledge of the methods available and how to access them. However, results from trials of behaviour change interventions have been disappointing. Three trials in SSA have evaluated the effectiveness of behaviour change interventions in reducing HIV, sexually transmitted infections (STIs) and pregnancies. A cluster randomised trial (CRT) in South Africa evaluating the Stepping Stones intervention found that women in the intervention arm had 1.45 times the odds of self-reported unplanned pregnancy after 24 months, although the increase was not statistically significant [95\% confidence interval (CI) 0.92-2.28; $p=0.11) .{ }^{11}$ A CRT in Tanzania evaluating the impact of the MEMA kwa Vijana intervention in adolescents aged 12-19 years found an effect on knowledge of pregnancy prevention, HIV acquisition and knowledge of STI acquisition and some reported behaviours, but did not show any effect on self-reported unplanned pregnancy or reported pregnancy at either 3 or 9 years after the intervention was introduced. ${ }^{12} 13$ Similarly, in Zimbabwe, the Regai Dzive Shiri intervention failed to show a significant effect on selfreported unwanted pregnancy among young women [adjusted odds ratio (adjOR) 0.88; 95\% CI $0.69-$ 1.12], despite having an impact on pregnancy-related knowledge and reported past or current pregnancy (adjOR 0.64; 95\% CI 0.49-0.83). ${ }^{14}$

Determining factors associated with unplanned pregnancy will help guide future intervention programmes. In this paper, we use data from the 2007/ 2008 long-term impact evaluation of the MEMA kwa Vijana intervention trial in Mwanza, Tanzania to explore factors associated with unplanned pregnancy.

\section{METHODS}

\section{Study design}

From June 2007 to July 2008, a cross-sectional study was conducted in 20 rural communities in the Mwanza region of Tanzania, near Lake Victoria. Each community consisted of about five or six villages, and equated approximately to an administrative ward. ${ }^{15}$ In 1999 2002, these 20 communities participated in the MEMA kwa Vijana ('good things for young people') CRT; 10 were randomised to receive the intervention, and the other 10 were comparison communities. The intervention included a participatory, teacher-led, peer-assisted, in-school programme, aiming to reduce the incidence of HIV, STIs and unplanned pregnancies. The intervention also included the provision of youth-friendly sexual and reproductive health services. The rationale and design of the trial and intervention have been described in detail elsewhere. ${ }^{1516}$ The intervention continued in the intervention communities after 2002, and was started in the comparison communities in 2005-2007, as part of the scale-up and operations research component of the MEMA kwa Vijana Programme. ${ }^{13}$

The primary aim of the cross-sectional survey was to assess the long-term impact of the intervention on the incidence of HIV, STIs and unplanned pregnancy and the results of these analyses have been published previously. ${ }^{13}$ The survey recruited young people who had attended at least one of school Years 5-7 in one of the trial communities between 1999 and 2002. An attempt was made to visit all the households in the trial communities and 16747 young people were invited to participate in the survey. In total, 13814 eligible young people, of which 6513 were women, attended the survey and were interviewed face-to-face by a same-sex research assistant about their sexual behaviour and knowledge and attitudes related to sexual health. There were 12 interviewers in total, who were trained for 3 weeks before conducting interviews.

In this paper we report the results of a secondary analysis looking at factors associated with unplanned pregnancy in sexually active young women in the intervention and comparison trial communities. Women were classified as sexually active if they reported ever having had sex, regardless of whether they were sexually active at the time of the survey. One section of the questionnaire was dedicated to contraception and included questions about pregnancy. Women who reported that they had ever had sex were asked whether they had ever been pregnant, whether they had ever had a pregnancy that was unplanned, and if they had been pregnant while attending primary school. The majority of the study population would have completed primary school when aged between 14 and 18 years. ${ }^{16}$ The primary outcome of interest for this analysis was reported unplanned pregnancy amongst all sexually active females. Two additional analyses were also conducted. First, to ensure our results were comparable with other studies we examined determinants of reported unplanned pregnancy in females aged 15-24 years old. Second, because of the difficulties in defining unplanned pregnancy, we looked at risk factors for reporting any pregnancy among never-married women, regardless of whether this was reported as unplanned. As the timing of the pregnancy was unknown, women who were previously married were not included in this subgroup as they may have become pregnant while married.

\section{Statistical methods}

Baseline characteristics for women were tabulated by whether they were never-married or ever-married. Since never-married women were much younger, the characteristics of the two groups of women were compared after adjusting for age using conditional logistic regression to account for within-community correlation.

Potential determinants of unplanned pregnancy were divided into three groups using a hierarchical framework ${ }^{17}$ : socio-demographic, knowledge of and reported attitudes related to sexual health, and reported sexual behaviour and contraceptive use. We did not gather data on age at which the unplanned 
pregnancy occurred; however, since current age was strongly associated with lifetime pregnancy, it was included in the analysis as a potential confounder. Knowledge of HIV, STI and pregnancy prevention, and attitudes towards sexual health, were assessed in the questionnaire through three questions on each topic which have been described elsewhere. ${ }^{13}$

Conditional logistic regression was used to estimate ORs and 95\% CIs for the association of exposures of interest with reported unplanned pregnancy amongst all women. Initial models included only the sociodemographic risk factors. Socio-demographic factors whose associations with unplanned pregnancy were significant at $p<0.10$ in univariate analyses were included in a multivariable model; those remaining independently associated at $p<0.10$ were retained in a core model. At the next level of the hierarchical framework, knowledge and attitude factors were added one by one to the core socio-demographic model. Those knowledge and attitude factors whose adjusted association with pregnancy was $p<0.10$ were included in the multivariable model; those remaining with $p<0.10$ were retained. Associations with reported sexual behaviour and contraceptive use factors were determined in a similar way. This strategy allowed us to assess the effects of variables at each level of the hierarchy, adjusted for more distal variables. Furthermore, it enabled us to evaluate the effects of distal variables prior to adjustment for more proximal mediating factors. Risk factors for unplanned pregnancy in 1524-year-old women and risk factors for any reported pregnancy amongst never-married women were determined using the same modelling procedure.

\section{Ethics approval}

The trial protocol received ethical and research clearance from the Tanzanian Medical Research Coordinating Committee and the London School of Hygiene and Tropical Medicine Ethics Committee. Signed informed consent was obtained from each participant on the day of the survey. Signed consent was also obtained from parents of participants under the age of 18 years.

\section{RESULTS}

\section{Baseline characteristics}

Data were available for 6513 women (aged 15-30 years) of whom $1742(26.7 \%)$ were sexually active and never married and 4319 (66.3\%) were sexually active and had ever been married. Four-hundred and fifty-two women reported that they had never had sex, and were excluded from further analyses. Nevermarried women were much younger, with $62.0 \%$ of this subgroup $<21$ years old compared with $27.2 \%$ of ever-married women. After adjusting for age, there was strong evidence that never-married women were different from ever-married women with respect to all the baseline characteristics (Table 1). Overall, 30.5\% of never-married women reported an unplanned pregnancy compared with $23.7 \%$ of ever-married women (Table 1). The prevalence of reported unplanned pregnancy amongst all women increased with age, from $21.3 \%$ of all women aged $<21$ years to $33.8 \%$ amongst women aged 25 years or over. Among the never-married women, $43.6 \%$ reported ever having been pregnant, and $69.9 \%$ of these 'everpregnant' women also reported having had at least one unplanned pregnancy. A higher proportion of nevermarried women reported having ever used modern contraceptives to prevent pregnancy than ever-married women $(65.3 \%$ vs $41.6 \%, p<0.001)$. Of the 1138 never-married women who reported ever having used modern contraceptives, $97.6 \%$ reported using condoms, $4.5 \%$ reported using oral contraceptive pills and $6.6 \%$ reported using injectable contraceptives. Amongst 1794 ever-married women reporting modern contraceptive use, $86.0 \%$ reported condom use, 9.6\% reported oral contraceptive pill use and $24.0 \%$ reported ever using injectable contraceptives.

\section{Risk factors for reported unplanned pregnancy amongst all women}

In the unadjusted analysis, socio-demographic factors associated with unplanned pregnancy were increasing age, lower educational level, not being currently married and occupation (highest among business women and lowest among students) (Table 2). In the adjusted analysis of socio-demographic factors, independent factors associated with unplanned pregnancy were increasing age, lower educational level and not being currently married. Occupation and education were strongly co-linear, so were not included in the model together; however, occupation was independently associated with unplanned pregnancy when education was dropped from the model.

In both the unadjusted and adjusted analysis of the sexual knowledge and reported attitudes factors, knowledge of where to access condoms was associated with unplanned pregnancy; no evidence of association was found with other knowledge or attitude factors (Table 3).

For the crude analysis of the reported sexual behaviour and contraceptive use factors, increased number of reported lifetime partners, younger reported age at sexual debut, reporting a casual partner in the past year, and reporting no regular partner in the past year were associated with unplanned pregnancy among all women (Table 4). After adjusting for sociodemographic and knowledge factors, only the associations with increasing number of lifetime partners and younger reported age at sexual debut remained.

\section{Risk factors for reported unplanned pregnancy amongst} women aged $\mathbf{1 5}-\mathbf{2 4}$ years

Identical risk factors were identified for unplanned pregnancy amongst women when the analysis was restricted to women aged 15-24 years. Effect 
Article

Table 1 Baseline characteristics of the study population

\begin{tabular}{|c|c|c|c|c|}
\hline Characteristic & $\begin{array}{l}\text { All women (including } \\
\text { non-sexually active) }(n=6513)\end{array}$ & $\begin{array}{l}\text { Sexually active, never-married } \\
\text { women }(n=1742)\end{array}$ & $\begin{array}{l}\text { Sexually active, } \\
\text { ever-married }(n=4319)\end{array}$ & $\begin{array}{l}\text { Age-adjusted } \\
\text { p value* }\end{array}$ \\
\hline \multicolumn{5}{|l|}{ Demographic } \\
\hline \multicolumn{5}{|l|}{ Age (years) $†$} \\
\hline$<21$ & $2641(40.6)$ & $1080(62.0)$ & $1176(27.2)$ & \\
\hline $21-22$ & $1864(28.6)$ & $430(24.7)$ & $1389(32.2)$ & \\
\hline$\geq 23$ & $2006(30.8)$ & $231(13.3)$ & $1754(40.6)$ & $<0.001$ \\
\hline \multicolumn{5}{|l|}{ Ethnicity ${ }^{+}$} \\
\hline Sukumał & $5295(81.4)$ & $1343(77.1)$ & $3620(83.9)$ & \\
\hline Non-Sukuma & $1212(18.6)$ & $399(22.9)$ & $693(16.1)$ & $<0.001$ \\
\hline \multicolumn{5}{|l|}{ Religiont } \\
\hline Christian & $5764(88.7)$ & $1604(92.1)$ & $3736(86.7)$ & \\
\hline Moslem & $278 \quad(4.3)$ & $102 \quad(5.9)$ & $161 \quad(3.7)$ & \\
\hline Other & $9(0.1)$ & $1(0.1)$ & $8 \quad(0.2)$ & \\
\hline None & $447 \quad(6.9)$ & $35 \quad(2.0)$ & $403 \quad(9.3)$ & $<0.001$ \\
\hline \multicolumn{5}{|l|}{ Highest education level† } \\
\hline Secondary/higher & $1234(19.0)$ & $740(42.5)$ & $181 \quad(4.2)$ & \\
\hline Primary & $5269(81.0)$ & $1000(57.5)$ & $4130(95.8)$ & $<0.001$ \\
\hline \multicolumn{5}{|l|}{ Occupation } \\
\hline Business & $812(12.5)$ & $266(15.3)$ & $505(11.8)$ & \\
\hline Housework/farming & $4470(69.0)$ & $788(45.3)$ & 3591 (83.6) & \\
\hline School/university & $801(12.4)$ & $515(29.6)$ & $13 \quad(0.3)$ & \\
\hline None/other & $400 \quad(6.2)$ & $169(9.7)$ & 186 & $<0.001$ \\
\hline \multicolumn{5}{|c|}{ Time slept away in the past year } \\
\hline Never & $3397(52.2)$ & $754(43.3)$ & $2451(56.8)$ & \\
\hline$<1$ month & $2116(32.5)$ & $604(34.7)$ & $1356(31.4)$ & \\
\hline $1-3$ months & 538 & $210(12.0)$ & $275 \quad(6.4)$ & \\
\hline$>3$ months & $462(7.1)$ & $174(10.0)$ & $237 \quad(5.5)$ & $<0.001$ \\
\hline \multicolumn{5}{|c|}{ Sexual knowledge and attitude } \\
\hline \multicolumn{5}{|c|}{ Know where to get condoms in village } \\
\hline No/Don't know & $1527(23.4)$ & $328(18.8)$ & $1028(23.8)$ & \\
\hline Yes & $4986(76.6)$ & $1414(81.2)$ & $3291(76.2)$ & $<0.001$ \\
\hline \multicolumn{5}{|c|}{ Know where to get free condoms in village } \\
\hline No/Don't know & $3739(57.4)$ & $894(51.3)$ & $2556(59.2)$ & \\
\hline Yes & $2774(42.6)$ & $848(48.7)$ & $1763(40.8)$ & $<0.001$ \\
\hline \multicolumn{5}{|c|}{ Knowledge of HIV acquisitiont } \\
\hline 3 correct & $4184(64.4)$ & $1202(69.3)$ & $2661(61.8)$ & \\
\hline 2 correct & $1959(30.2)$ & $460(26.5)$ & $1385(32.2)$ & \\
\hline 1 correct & $318(4.9)$ & $64 \quad(3.7)$ & $240 \quad(5.6)$ & \\
\hline 0 correct & $32(0.5)$ & $9(0.5)$ & $21 \quad(0.5)$ & $<0.001$ \\
\hline \multicolumn{5}{|c|}{ Knowledge of STI acquisitiont } \\
\hline 3 correct & $2227(34.3)$ & $761(43.8)$ & $1275(29.6)$ & \\
\hline 2 correct & $2656(40.9)$ & $602(34.7)$ & $1898(44.1)$ & \\
\hline 1 correct & $1393(21.4)$ & $333(19.2)$ & $969(22.5)$ & \\
\hline 0 correct & $219(3.4)$ & $41 \quad(2.4)$ & $165 \quad(3.8)$ & $<0.001$ \\
\hline \multicolumn{5}{|c|}{ Knowledge of pregnancy preventiont } \\
\hline 3 correct & $4237(65.2)$ & $1247(71.7)$ & $2699(62.7)$ & \\
\hline 2 correct & $1702(26.2)$ & $384(22.1)$ & $1194(27.7)$ & \\
\hline 1 correct & $471 \quad(7.3)$ & $99 \quad(5.7)$ & $341 \quad(7.9)$ & \\
\hline 0 correct & $87 \quad(1.3)$ & $10(0.6)$ & $71 \quad(1.7)$ & $<0.001$ \\
\hline \multicolumn{5}{|c|}{ Attitude towards sexual health $\dagger$} \\
\hline 3 correct & $691(10.6)$ & $231(13.3)$ & $383 \quad(8.9)$ & \\
\hline 2 correct & $2178(33.5)$ & $634(36.4)$ & 1361 (31.6) & \\
\hline 1 correct & $2515(38.7)$ & $659(37.9)$ & 1707 (39.6) & \\
\hline 0 correct & $1119(17.2)$ & $217(12.4)$ & $859(19.9)$ & $<0.001$ \\
\hline
\end{tabular}




\begin{tabular}{|c|c|c|c|c|}
\hline & $\begin{array}{l}\text { All sexually active } \\
\text { women }(n=6061)\end{array}$ & $\begin{array}{l}\text { Sexually active, never-married } \\
\text { women }(n=1742)\end{array}$ & $\begin{array}{l}\text { Sexually active, } \\
\text { ever-married }(n=4319)\end{array}$ & $\begin{array}{l}\text { Age-adjusted } \\
\text { p value* }\end{array}$ \\
\hline \multicolumn{5}{|l|}{ Reported sexual behaviour§ } \\
\hline \multicolumn{5}{|c|}{ Lifetime number of pregnancies $(n)$} \\
\hline 0 & $1171(19.4)$ & $982(56.4)$ & 189 (4.4) & \\
\hline 1 & $1817(30.1)$ & $571(32.8)$ & $1246(29.0)$ & \\
\hline 2 & $1857(30.8)$ & $162(9.3)$ & 1695 (39.5) & \\
\hline$\geq 3$ & $1192(19.7)$ & $27 \quad(1.6)$ & $1165(27.1)$ & $<0.001$ \\
\hline \multicolumn{5}{|l|}{ Unplanned pregnancy } \\
\hline No & $4477(74.3)$ & $1208(69.5)$ & $3269(76.3)$ & \\
\hline Yes & $1547(25.7)$ & $531(30.5)$ & $1016(23.7)$ & $<0.001$ \\
\hline \multicolumn{5}{|c|}{ Reported pregnant at primary school } \\
\hline No & $5868(96.8)$ & $1714(98.4)$ & $4154(96.2)$ & \\
\hline Yes & 192 (3.2) & $28 \quad(1.6)$ & 165 & $<0.001$ \\
\hline \multicolumn{5}{|l|}{ Lifetime number of partners $(n)$} \\
\hline 1 & $1837(30.4)$ & $750(43.1)$ & $1087(25.3)$ & \\
\hline $2-4$ & $3631(60.1)$ & $851(48.9)$ & $2780(64.6)$ & \\
\hline$\geq 5$ & 575 (9.5) & $141 \quad(8.1)$ & $434(10.1)$ & $<0.001$ \\
\hline \multicolumn{5}{|l|}{ Age at sexual debut (years) } \\
\hline$\geq 16$ & $4271(70.7)$ & $1273(73.3)$ & $2998(69.7)$ & \\
\hline$<16$ & $1768(29.3)$ & $463(26.7)$ & $1305(30.3)$ & $<0.001$ \\
\hline \multicolumn{5}{|c|}{ Had a casual partner in the past 12 months } \\
\hline No & $5164(85.4)$ & $1243(71.4)$ & $3921(91.1)$ & \\
\hline Yes & $882(14.6)$ & $497(28.6)$ & 385 (8.9) & $<0.001$ \\
\hline \multicolumn{5}{|c|}{ Had a regular partner in the past 12 months } \\
\hline No & $836(13.8)$ & $634(36.4)$ & $202(4.7)$ & \\
\hline Yes & $5210(86.2)$ & $1106(63.6)$ & $4104(95.3)$ & $<0.001$ \\
\hline \multicolumn{5}{|c|}{ Ever used modern contraception to prevent pregnancy } \\
\hline Yesף & $2932(48.5)$ & $1138(65.3)$ & $1794(41.6)$ & \\
\hline Condom & $2654(90.5)$ & $1111(97.6)$ & $1543(86.0)$ & \\
\hline Oral contraceptive pill & $224(7.6)$ & 51 (4.5) & 173 (9.6) & \\
\hline Injectable contraceptives & $505(17.2)$ & 75 (6.6) & $430(24.0)$ & \\
\hline No & $3119(51.5)$ & $604(34.7)$ & $2515(58.4)$ & $<0.001$ \\
\hline
\end{tabular}

* Comparing the baseline characteristics in the never-married, sexually active women with the ever-married, sexually active women. tMissing $<10$ values.

¥The Sukuma are the largest ethnic group in Tanzania, comprising 16\% of the population, and they are the predominant group in north-western Tanzania. §For all women the analysis was restricted to the 6061 women who were sexually active.

ף|lt was possible for women to report using multiple different types of contraceptives to prevent pregnancy; the percentage of each type of modern contraceptive are out of all those that reported using modern contraceptives to prevent pregnancy.

STI, sexually transmitted infection.

estimates were very similar $(<10 \%$ difference), except for that of increasing number of partners which was slightly attenuated (adjOR $=2.39$, CI 1.89-3.04, comparing $5+$ partners to one, vs adjOR $=2.93$, CI 2.343.68 , in the analysis of all women). Results are reported in Tables 5-7.

\section{Risk factors for reported pregnancy amongst never-married women}

In adjusted analyses, independent socio-demographic factors associated with pregnancy among nevermarried women were increasing age, lower educational level, occupation (highest among housework/ farmer and lowest amongst students) and decreased time spent away from the community (Tables 8-10).
After adjusting for the socio-demographic predictors, the only sexual knowledge and reported attitudes factor that was weakly associated with increased risk of an unplanned pregnancy was knowledge of where to access condoms in the village. Finally, increasing reported lifetime partners, not using modern contraceptives to prevent pregnancy and not having a casual sexual partner in the past year were associated with pregnancy after adjusting for socio-demographic and knowledge factors.

\section{DISCUSSION}

Whilst several large intervention studies have been conducted aiming to reduce the prevalence of unplanned pregnancies, there have been very few 
Table 2 Association of socio-demographic risk factors with unplanned pregnancy in all sexually active women

\begin{tabular}{|c|c|c|c|c|c|c|}
\hline Socio-demographic factor & Women $(n)$ & $\begin{array}{l}\text { Unplanned } \\
\text { pregnancy (\%) }\end{array}$ & $\begin{array}{l}\text { Crude OR } \\
(95 \% \mathrm{Cl})\end{array}$ & $p$ & $\begin{array}{l}\text { Adjusted OR* } \\
(95 \% \mathrm{Cl})\end{array}$ & $p$ \\
\hline \multicolumn{7}{|l|}{ Age (years) } \\
\hline$<21$ & 2242 & 21.3 & 1 & & 1 & \\
\hline $21-22$ & 1805 & 26.2 & $1.31(1.13-1.51)$ & & $1.41(1.21-1.64)$ & \\
\hline$\geq 23$ & 1976 & 30.2 & $1.59(1.39-1.84)$ & $<0.001$ & $1.82(1.56-2.12)$ & $<0.001$ \\
\hline \multicolumn{7}{|l|}{ Ethnic groupt } \\
\hline Sukuma & 4934 & 25.6 & 1 & & 1 & \\
\hline Non-Sukuma & 1090 & 26.2 & $1.03(0.87-1.22)$ & 0.70 & $1.08(0.91-1.29)$ & 0.37 \\
\hline \multicolumn{7}{|l|}{ Religion } \\
\hline Christian & 5313 & 25.9 & 1 & & 1 & \\
\hline Other & 706 & 23.9 & $0.96(0.79-1.16)$ & 0.64 & $0.91(0.75-1.11)$ & 0.36 \\
\hline \multicolumn{7}{|l|}{ Highest level of education } \\
\hline Secondary/higher & 912 & 16.6 & 1 & & 1 & \\
\hline Primary & 5108 & 27.3 & $1.97(1.63-2.37)$ & $<0.001$ & $2.79(2.26-3.44)$ & $<0.001$ \\
\hline \multicolumn{7}{|l|}{ Occupation $\ddagger$} \\
\hline Business & 769 & 29.8 & 1 & & 1 & \\
\hline Housework/farming & 4360 & 27.5 & $0.95(0.80-1.13)$ & & $1.18(0.99-1.41)$ & \\
\hline School/university & 522 & 4.4 & $0.11(0.07-0.17)$ & & $0.08(0.05-0.12)$ & \\
\hline None/other & 351 & 27.4 & $0.93(0.70-1.24)$ & $<0.001$ & $0.87(0.65-1.16)$ & $<0.001$ \\
\hline \multicolumn{7}{|l|}{ Time slept away in the past year } \\
\hline Never & 3193 & 25.6 & 1 & & 1 & \\
\hline$<1$ month & 1949 & 25.5 & $0.97(0.85-1.10)$ & & $0.99(0.87-1.13)$ & \\
\hline $1-3$ months & 480 & 25.4 & $0.97(0.78-1.21)$ & & $0.96(0.76-1.21)$ & \\
\hline$>3$ months & 402 & 28.1 & $1.07(0.85-1.36)$ & 0.85 & $1.08(0.85-1.38)$ & 0.88 \\
\hline \multicolumn{7}{|l|}{ Marital status } \\
\hline Currently married & 3660 & 21.6 & 1 & & 1 & \\
\hline Never married & 1739 & 30.5 & $1.54(1.35-1.76)$ & & $2.67(2.29-3.11)$ & \\
\hline Previously married & 625 & 35.8 & $1.99(1.66-2.39)$ & $<0.001$ & $2.01(2.26-3.44)$ & $<0.001$ \\
\hline
\end{tabular}

${ }^{*}$ Adjusted for independent socio-demographic risk factors for unplanned pregnancy: age, education and marital status.

†The Sukuma are the largest ethnic group in Tanzania, comprising 16\% of the population, and they are the predominant group in north-western Tanzania. $\ddagger$ Adjusted for all independent predictors of pregnancy listed in the first footnote except for education.

$\mathrm{Cl}$, confidence interval; OR, odds ratio.

studies that have examined risk factors for unplanned pregnancy, particularly in SSA. This study identified a number of socio-demographic and behavioural risk factors for reported unplanned pregnancy amongst all sexually active women participating in a CRT in Mwanza region, Tanzania. Increasing age, lower educational level, not being currently married, knowledge about condom access, increasing number of sexual partners, and younger reported age at sexual debut were all predictors of unplanned pregnancy.

Several studies have looked at whether educational level is associated with unplanned pregnancy and the results have been inconsistent. A study in Nigeria found that better educated women had higher odds of reported unplanned pregnancy, ${ }^{18}$ while in a study in the USA lower educational level was associated with unplanned pregnancy, consistent with our findings. ${ }^{19}$ One possible pathway by which higher educational level may decrease the risk of unplanned pregnancy is by increasing sexual health knowledge. However, in our study, none of the variables measuring knowledge of sexual health factors were associated with unplanned pregnancy; although there was strong evidence that knowledge of where to access condoms is associated with increased risk of unplanned pregnancy. This may represent reverse causality, with women finding out about condoms after having an unplanned pregnancy. Our findings support previous research that has found improved knowledge of sexual health does not necessarily translate into practising family

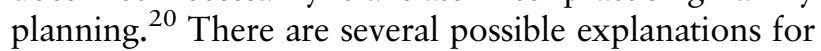
the observed association between higher educational level and decreased odds of unplanned pregnancy. First, this could be due to mediation by features of knowledge or skills not captured in this study such as self-efficacy and negotiation skills. The assessment of sexual health knowledge was limited to only three questions on each sexual health knowledge domain and consequently was not comprehensive. The questions on pregnancy prevention, for example, only focused on condom use and not on any other contraceptive methods. An alternative explanation for the observed association between education and unplanned pregnancy is that women who continue in 
Table 3 Association of knowledge of and attitude to sexual health factors with unplanned pregnancy in all sexually active women

\begin{tabular}{|c|c|c|c|c|c|c|}
\hline $\begin{array}{l}\text { Knowledge of and attitude to } \\
\text { sexual health factors }\end{array}$ & Women $(n)$ & $\begin{array}{l}\text { Unplanned } \\
\text { pregnancy (\%) }\end{array}$ & $\begin{array}{l}\text { Crude OR } \\
(95 \% \mathrm{Cl})\end{array}$ & $p$ & $\begin{array}{l}\text { Adjusted OR } \\
(95 \% \mathrm{Cl})^{*}\end{array}$ & $p$ \\
\hline \multicolumn{7}{|l|}{$\begin{array}{l}\text { Knowledge of where to access } \\
\text { condoms in village }\end{array}$} \\
\hline Yes & 4683 & 26.4 & 1 & & 1 & \\
\hline No/Don't know & 1341 & 23.0 & $0.87(0.75-1.00)$ & 0.05 & $0.81(0.70-0.94)$ & 0.005 \\
\hline \multicolumn{7}{|l|}{$\begin{array}{l}\text { Knowledge of where to access } \\
\text { free condoms in village }\end{array}$} \\
\hline Yes & 2601 & 26.3 & 1 & & 1 & \\
\hline No/Don't know & 3423 & 25.2 & $0.95(0.84-1.07)$ & 0.39 & $0.95(0.83-1.09)$ & 0.50 \\
\hline \multicolumn{7}{|l|}{ Knowledge of HIV acquisition } \\
\hline 3 correct & 3845 & 26.5 & 1 & & 1 & \\
\hline $0-2$ correct & 2167 & 24.3 & $0.92(0.81-1.04)$ & 0.19 & $0.90(0.79-1.03)$ & 0.12 \\
\hline \multicolumn{7}{|l|}{ Knowledge of STI acquisition } \\
\hline 3 correct & 2025 & 26.9 & 1 & & 1 & \\
\hline $0-2$ correct & 3989 & 25.0 & $0.95(0.84-1.08)$ & 0.41 & $0.91(0.80-1.04)$ & 0.17 \\
\hline \multicolumn{7}{|l|}{ Knowledge of pregnancy prevention } \\
\hline 3 correct & 3928 & 25.8 & 1 & & 1 & \\
\hline $0-2$ correct & 2087 & 25.4 & $1.02(0.90-1.16)$ & 0.71 & $1.05(0.92-1.20)$ & 0.45 \\
\hline \multicolumn{7}{|l|}{ Attitude towards sexual health } \\
\hline 3 correct & 608 & 23.5 & 1 & & 1 & \\
\hline $0-2$ correct & 5413 & 25.9 & $1.17(0.96-1.43)$ & 0.12 & $1.06(0.86-1.30)$ & 0.58 \\
\hline
\end{tabular}

${ }^{*}$ Adjusted for age, education, marital status and knowledge of where to access to condoms in the village.

$\mathrm{Cl}$, confidence interval; OR, odds ratio; STI, sexually transmitted infection.

education may have aspirations to have a career and are therefore more likely to try to avoid pregnancy due to the high chance of being forced to leave school if they become pregnant, either by the school or by their family. ${ }^{9}$ Possibly, some of the observed association could be explained by reverse causality, with women leaving school because they have become pregnant; however, a very small minority of pregnancies were reported to have occurred at primary school so this is unlikely to explain all the association seen.

We found that increasing current age was associated with unplanned pregnancy; however, this likely reflects the fact that older women have had more chance of a lifetime unplanned pregnancy, rather than

Table 4 Association of reported sexual behaviours and contraceptive use with unplanned pregnancy in all sexually active women

\begin{tabular}{|c|c|c|c|c|c|c|}
\hline Reported sexual behaviours and contraceptive use & Women $(n)$ & $\begin{array}{l}\text { Unplanned } \\
\text { pregnancy (\%) }\end{array}$ & $\begin{array}{l}\text { Crude OR } \\
(95 \% \mathrm{Cl})\end{array}$ & $p$ & $\begin{array}{l}\text { Adjusted OR } \\
(95 \% \mathrm{Cl})^{*}\end{array}$ & $p$ \\
\hline \multicolumn{7}{|l|}{ Age at first sex (years) } \\
\hline$\geq 16$ & 4253 & 24.2 & 1 & & 1 & \\
\hline$<16$ & 1762 & 29.5 & $1.28(1.13-1.45)$ & $<0.001$ & $1.31(1.15-1.51)$ & $<0.001$ \\
\hline \multicolumn{7}{|l|}{ Lifetime number of partners $(n)$} \\
\hline 1 & 1825 & 16.4 & 1 & & 1 & \\
\hline $2-4$ & 3626 & 28.1 & $1.95(1.69-2.25)$ & & $2.13(1.83-2.49)$ & \\
\hline$\geq 5$ & 572 & 39.9 & $3.28(2.65-4.04)$ & $<0.001$ & $2.93(2.34-3.68)$ & $<0.001$ \\
\hline \multicolumn{7}{|l|}{ Ever used modern contraceptive to prevent pregnancy } \\
\hline Yes & 2923 & 26.6 & 1 & & 1 & \\
\hline No & 3101 & 24.9 & $0.94(0.84-1.06)$ & 0.34 & $1.09(0.95-1.26)$ & 0.20 \\
\hline \multicolumn{7}{|l|}{ Casual partner in the past year } \\
\hline No & 5144 & 24.6 & 1 & & 1 & \\
\hline Yes & 878 & 31.9 & $1.43(1.22-1.67)$ & $<0.001$ & $0.88(0.73-1.05)$ & 0.15 \\
\hline \multicolumn{7}{|l|}{ Regular partner in the past year } \\
\hline No & 830 & 30.4 & 1 & & 1 & \\
\hline Yes & 5192 & 24.9 & $0.77(0.65-0.90)$ & 0.002 & $0.97(0.81-1.18)$ & 0.70 \\
\hline
\end{tabular}

${ }^{*}$ Adjusted for age, marital status, education, knowledge of where to access to condoms in the village, lifetime number of partners and age at first sex. $\mathrm{Cl}$, confidence interval; OR, odds ratio. 
Table 5 Association of socio-demographic risk factors with reported unplanned pregnancy in all sexually active women aged $15-24$ years

\begin{tabular}{|c|c|c|c|c|c|c|}
\hline Socio-demographic factor & Women $(n)$ & $\begin{array}{l}\text { Unplanned } \\
\text { pregnancy (\%) }\end{array}$ & $\begin{array}{l}\text { Crude OR } \\
(95 \% \mathrm{Cl})\end{array}$ & $p$ & $\begin{array}{l}\text { Adjusted OR* } \\
(95 \% \mathrm{Cl})\end{array}$ & $p$ \\
\hline \multicolumn{7}{|l|}{ Age (years) } \\
\hline$<21$ & 2242 & 21.3 & 1 & & 1 & \\
\hline $21-22$ & 1805 & 26.2 & $1.31(1.13-1.51)$ & & $1.41(1.21-1.64)$ & \\
\hline $23-24$ & 1473 & 29.0 & $1.51(1.29-1.76)$ & $<0.001$ & $1.72(1.46-2.03)$ & $<0.001$ \\
\hline \multicolumn{7}{|l|}{ Ethnic group } \\
\hline Sukuma & 4513 & 24.9 & 1 & & 1 & \\
\hline Non-Sukuma & 1007 & 25.2 & $1.00(0.84-1.20)$ & 0.98 & $1.04(0.87-1.25)$ & 0.65 \\
\hline \multicolumn{7}{|l|}{ Religion } \\
\hline Christian & 4886 & 25.2 & 1 & & 1 & \\
\hline Other & 630 & 22.5 & $0.91(0.75-1.12)$ & 0.38 & $0.87(0.71-1.07)$ & 0.19 \\
\hline \multicolumn{7}{|l|}{ Highest level of education } \\
\hline Secondary/higher & 898 & 16.6 & 1 & & 1 & \\
\hline Primary & 4618 & 26.6 & $1.90(0.57-2.29)$ & $<0.001$ & $2.77(2.24-3.43)$ & $<0.001$ \\
\hline \multicolumn{7}{|l|}{ Occupationt } \\
\hline Business & 708 & 28.8 & 1 & & 1 & \\
\hline Housework/farming & 3935 & 26.8 & $0.97(0.81-1.17)$ & & $1.22(1.01-1.47)$ & \\
\hline School/university & 521 & 4.4 & $0.11(0.07-0.18)$ & & $0.08(0.05-0.12)$ & \\
\hline None/other & 335 & 27.5 & $0.98(0.73-1.32)$ & $<0.001$ & $0.92(0.68-1.24)$ & $<0.001$ \\
\hline \multicolumn{7}{|l|}{ Time slept away in the past year } \\
\hline Never & 2903 & 25.0 & 1 & & 1 & \\
\hline$<1$ month & 1789 & 24.4 & $0.94(0.82-1.08)$ & & $0.96(0.84-1.11)$ & \\
\hline $1-3$ months & 453 & 24.7 & $0.96(0.76-1.21)$ & & $0.94(0.74-1.20)$ & \\
\hline$>3$ months & 375 & 26.9 & $1.04(0.81-1.33)$ & 0.81 & $1.04(0.81-1.35)$ & 0.89 \\
\hline \multicolumn{7}{|l|}{ Marital status } \\
\hline Currently married & 3268 & 20.7 & 1 & & 1 & \\
\hline Never married & 1695 & 30.0 & $1.58(1.38-1.82)$ & & $2.67(2.28-3.13)$ & \\
\hline Previously married & 557 & 34.5 & $1.99(1.63-2.42)$ & $<0.001$ & $2.01(1.65-2.44)$ & $<0.001$ \\
\hline
\end{tabular}

${ }^{*}$ Adjusted for independent socio-demographic risk factors for unplanned pregnancy: age, education and marital status.

†The Sukuma are the largest ethnic group in Tanzania, comprising $16 \%$ of the population, and they are the predominant group in north-western Tanzania. $\ddagger$ Adjusted for all independent predictors of pregnancy listed in the first footnote, except for education.

$\mathrm{Cl}$, confidence interval; OR, odds ratio.

the actual age at pregnancy. We did not gather data on the age at which the unplanned pregnancy occurred, since recall of age is very poor, and many respondents in this population are unsure of their current age. We also found that not being currently married was associated with unplanned pregnancy, which has previously been shown in a number of studies. ${ }^{21} 22$

Several of the reported sexual behaviours showed patterns of association with unplanned pregnancy that differed from previous studies. Unlike several previous studies that found no association between lifetime number of partners and unplanned pregnancy ${ }^{19} 21$ we found that an increasing reported lifetime number of partners was associated with unplanned pregnancy, most likely because women who had a higher lifetime number of partners were likely to have had more sexual exposures and/or higher risk behaviours, such as not using contraceptives. Early sexual debut was a risk factor for reported unplanned pregnancy consistent with a study conducted in Zimbabwe. ${ }^{21}$
Analysis of the predictors of reported pregnancy in never-married females yielded very similar results to the predictors of unplanned pregnancy in all sexually active women. Two additional determinants of pregnancy that were identified in this subgroup were not having had a casual partner in the past year and not using modern contraceptives to prevent pregnancy. The observed inverse association between sex with a casual partner in the previous year and pregnancy might be explained by lower levels of sexual activity among women who have a casual partner compared with women who have a regular partner.

The study's strengths include the large sample size and the high number of potential risk factors for which data were collected. Furthermore, the hierarchical analysis method enabled causal pathways to be examined. However, as with any study, the results of such analyses need to be interpreted with caution, in light of the limitations. The cross-sectional nature of this study meant that temporal relationships could not be examined and consequently the relevance of some 
Table 6 Association of knowledge of and attitude to sexual health factors with reported unplanned pregnancy in all sexually active women aged $15-24$ years

\begin{tabular}{|c|c|c|c|c|c|c|}
\hline Knowledge of and attitude to sexual health factors & Women $(n)$ & $\begin{array}{l}\text { Unplanned } \\
\text { pregnancy (\%) }\end{array}$ & $\begin{array}{l}\text { Crude OR } \\
(95 \% \mathrm{Cl})\end{array}$ & $p$ & $\begin{array}{l}\text { Adjusted OR } \\
(95 \% \mathrm{Cl})^{*}\end{array}$ & $p$ \\
\hline \multicolumn{7}{|l|}{ Knowledge of where to access condoms in village } \\
\hline Yes & 4313 & 25.6 & 1 & & 1 & \\
\hline No/Don't know & 1207 & 22.8 & $0.90(0.77-1.04)$ & 0.16 & $0.84(0.72-0.98)$ & 0.03 \\
\hline \multicolumn{7}{|l|}{ Knowledge of where to access free condoms in village } \\
\hline Yes & 2392 & 25.3 & 1 & & 1 & \\
\hline No/Don't know & 3128 & 24.7 & $0.98(0.86-1.11)$ & 0.70 & $0.97(0.84-1.12)$ & 0.67 \\
\hline \multicolumn{7}{|l|}{ Knowledge of HIV acquisition } \\
\hline 3 correct & 3532 & 25.7 & 1 & & 1 & \\
\hline $0-2$ correct & 1976 & 23.6 & $0.93(0.82-1.06)$ & 0.30 & $0.90(0.80-1.04)$ & 0.15 \\
\hline \multicolumn{7}{|l|}{ Knowledge of STI acquisition } \\
\hline 3 correct & 1877 & 25.8 & 1 & & 1 & \\
\hline $0-2$ correct & 3634 & 24.5 & $0.98(0.86-1.12)$ & 0.79 & $0.94(0.82-1.08)$ & 0.37 \\
\hline \multicolumn{7}{|l|}{ Knowledge of pregnancy prevention } \\
\hline 3 correct & 3585 & 25.1 & 1 & & 1 & \\
\hline $0-2$ correct & 1926 & 24.7 & $1.03(0.90-1.17)$ & 0.70 & $1.05(0.91-1.20)$ & 0.53 \\
\hline \multicolumn{7}{|l|}{ Attitude towards sexual health } \\
\hline 3 correct & 568 & 22.9 & 1 & & 1 & \\
\hline $0-2$ correct & 4949 & 25.2 & $1.17(0.95-1.44)$ & 0.14 & $1.05(0.85-1.31)$ & 0.64 \\
\hline
\end{tabular}

${ }^{*}$ Adjusted for age, education, marital status and knowledge of where to access to condoms in the village.

$\mathrm{Cl}$, confidence interval; OR, odds ratio; STI, sexually transmitted infection.

of the risk factors (such as reporting $\geq 1$ casual partner in the past year) is unclear. Furthermore, unplanned pregnancy is a complex and heterogeneous concept, encompassing both mistimed and unwanted pregnancies. $^{20}$ It is further complicated as retrospective reports of whether a pregnancy was unplanned or unwanted may be influenced by the outcome of the pregnancy and the presence of the infant. ${ }^{23}$
Therefore, recall bias is a potential concern. Additionally, information was not available on the age of the woman when she had a reported unplanned pregnancy. Finally, 3466 of the 16747 young people invited for interviews did not attend; 1453 (42\%) were women. These women who did not participate may have been different from those who were included in the study, potentially biasing the results.

Table 7 Association of reported sexual behaviours and contraceptive use with reported unplanned pregnancy in all sexually active women aged $15-24$ years

\begin{tabular}{|c|c|c|c|c|c|c|}
\hline Reported sexual behaviours and contraceptive use & Women $(n)$ & $\begin{array}{l}\text { Unplanned } \\
\text { pregnancy (\%) }\end{array}$ & $\begin{array}{l}\text { Crude OR } \\
(95 \% \mathrm{Cl})\end{array}$ & $p$ & $\begin{array}{l}\text { Adjusted OR } \\
(95 \% \mathrm{Cl})^{*}\end{array}$ & $p$ \\
\hline \multicolumn{7}{|l|}{ Age at first sex (years) } \\
\hline$\geq 16$ & 3826 & 23.2 & 1 & & 1 & \\
\hline$<16$ & 1686 & 29.1 & $1.32(1.16-1.51)$ & $<0.001$ & $1.26(1.09-1.45)$ & 0.002 \\
\hline \multicolumn{7}{|l|}{ Lifetime number of partners $(n)$} \\
\hline 1 & 1734 & 16.1 & 1 & & 1 & \\
\hline $2-4$ & 3270 & 27.6 & $1.96(1.69-2.28)$ & & $1.77(1.51-2.07)$ & \\
\hline$\geq 5$ & 515 & 38.1 & $3.14(2.51-3.91)$ & $<0.001$ & $2.39(1.89-3.04)$ & $<0.001$ \\
\hline \multicolumn{7}{|l|}{ Ever used modern contraceptive to prevent pregnancy } \\
\hline Yes & 2712 & 25.4 & 1 & & 1 & \\
\hline No & 2808 & 24.5 & $0.99(0.87-1.12)$ & 0.81 & $1.15(1.00-1.33)$ & 0.05 \\
\hline \multicolumn{7}{|l|}{ Casual partner in the past year } \\
\hline No & 4694 & 24.0 & 1 & & 1 & \\
\hline Yes & 824 & 30.7 & $1.40(1.19-1.66)$ & $<0.001$ & $0.87(0.72-1.05)$ & 0.15 \\
\hline \multicolumn{7}{|l|}{ Regular partner in the past year } \\
\hline No & 790 & 29.6 & 1 & & 1 & \\
\hline Yes & 4728 & 24.2 & $0.77(0.65-0.91)$ & 0.002 & $0.98(0.80-1.19)$ & 0.84 \\
\hline
\end{tabular}

${ }^{*}$ Adjusted for age, marital status, education, knowledge of where to access to condoms in the village, lifetime number of partners and age at first sex. $\mathrm{Cl}$, confidence interval; $\mathrm{OR}$, odds ratio. 
Article

Table 8 Association of socio-demographic risk factors with any pregnancy in sexually active, never-married women

\begin{tabular}{|c|c|c|c|c|c|c|}
\hline Socio-demographic factor & Women $(n)$ & Pregnancy (\%) & Crude OR (95\% Cl) & $p$ & Adjusted OR $(95 \% \mathrm{Cl})^{*}$ & $p$ \\
\hline \multicolumn{7}{|l|}{ Age (years) } \\
\hline$<21$ & 1080 & 30.7 & 1 & & 1 & \\
\hline $21-22$ & 430 & 57.4 & $2.96 \quad(2.34-3.75)$ & & $2.79(2.14-3.62)$ & \\
\hline$\geq 23$ & 231 & 78.8 & 8.09 (5.73-11.44) & $<0.001$ & $6.01(4.12-8.76)$ & $<0.001$ \\
\hline \multicolumn{7}{|l|}{ Ethnic groupt } \\
\hline Sukuma & 1343 & 45.6 & 1 & & 1 & \\
\hline Non-Sukuma & 399 & 37.1 & $0.74 \quad(0.57-0.95)$ & 0.02 & $1.00(0.74-1.35)$ & 0.99 \\
\hline \multicolumn{7}{|l|}{ Religion } \\
\hline Christian & 1604 & 43.2 & 1 & & 1 & \\
\hline Other & 138 & 48.6 & $1.27 \quad(0.89-1.82)$ & 0.19 & $1.03(0.67-1.57)$ & 0.90 \\
\hline \multicolumn{7}{|l|}{ Highest level of education } \\
\hline Secondary/higher & 745 & 17.3 & 1 & & 1 & \\
\hline Primary & 995 & 63.3 & $7.82 \quad(6.19-9.88)$ & $<0.001$ & $6.34(4.96-8.11)$ & $<0.001$ \\
\hline \multicolumn{7}{|l|}{ Occupationt } \\
\hline Business & 266 & 54.5 & 1 & & 1 & \\
\hline Housework/farming & 788 & 66.8 & $1.76 \quad(1.31-2.36)$ & & $1.82(1.33-2.50)$ & \\
\hline School/university & 515 & 4.1 & $0.04 \quad(0.02-0.06)$ & & $0.05(0.03-0.08)$ & \\
\hline None/other & 169 & 40.2 & $0.57 \quad(0.38-0.84)$ & $<0.001$ & $0.60(0.39-0.91)$ & $<0.001$ \\
\hline \multicolumn{7}{|l|}{ Time slept away in the past year } \\
\hline Never & 754 & 50.9 & 1 & & 1 & \\
\hline$<1$ month & 604 & 39.6 & $0.67 \quad(0.53-0.83)$ & & $0.71(0.55-0.92)$ & \\
\hline $1-3$ months & 210 & 35.2 & $0.52 \quad(0.38-0.72)$ & & $0.60(0.41-0.88)$ & \\
\hline$>3$ months & 163 & 38.0 & $0.58 \quad(0.40-0.82)$ & $<0.001$ & $0.74(0.49-1.11)$ & 0.01 \\
\hline
\end{tabular}

${ }^{*}$ Adjusted for independent socio-demographic risk factors for pregnancy amongst never-married women: age, education and time slept away in the past year.

†The Sukuma are the largest ethnic group in Tanzania, comprising 16\% of the population, and they are the predominant group in north-western Tanzania. $\ddagger$ Adjusted for all independent predictors of pregnancy listed in the first footnote, except for education.

$\mathrm{Cl}$, confidence interval; OR, odds ratio.

Table 9 Association of knowledge of and attitude to sexual health factors with pregnancy in sexually active, never-married women

\begin{tabular}{|c|c|c|c|c|c|c|}
\hline $\begin{array}{l}\text { Knowledge of and attitude to sexual health } \\
\text { factors }\end{array}$ & $\begin{array}{l}\text { Women } \\
(n)\end{array}$ & $\begin{array}{l}\text { Pregnancy } \\
(\%)\end{array}$ & $\begin{array}{l}\text { Crude OR } \\
(95 \% \mathrm{Cl})\end{array}$ & $p$ & $\begin{array}{l}\text { Adjusted OR } \\
(95 \% \mathrm{Cl})^{*}\end{array}$ & $p$ \\
\hline \multicolumn{7}{|l|}{ Knowledge of where to access condoms in village } \\
\hline Yes & 1414 & 42.3 & 1 & & 1 & \\
\hline No/Don't know & 328 & 49.4 & $1.28(1.00-1.63)$ & 0.05 & $0.78(0.58-1.04)$ & 0.09 \\
\hline \multicolumn{7}{|l|}{ Knowledge of where to access free condoms in village } \\
\hline Yes & 848 & 37.7 & 1 & & 1 & \\
\hline No/Don't know & 894 & 49.2 & $1.51(1.24-1.84)$ & $<0.001$ & $1.23(0.96-1.60)$ & 0.11 \\
\hline \multicolumn{7}{|l|}{ Knowledge of HIV acquisition } \\
\hline 3 correct & 1202 & 40.9 & 1 & & 1 & \\
\hline $0-2$ correct & 533 & 49.9 & $1.43(1.16-1.76)$ & 0.001 & $1.14(0.88-1.47)$ & 0.32 \\
\hline \multicolumn{7}{|l|}{ Knowledge of STI acquisition } \\
\hline 3 correct & 761 & 37.1 & 1 & & 1 & \\
\hline $0-2$ correct & 976 & 48.7 & $1.54(1.26-1.88)$ & $<0.001$ & $1.09(0.86-1.39)$ & 0.47 \\
\hline \multicolumn{7}{|l|}{ Knowledge of pregnancy prevention } \\
\hline 3 correct & 1247 & 40.9 & 1 & & 1 & \\
\hline $0-2$ correct & 493 & 50.5 & $1.38(1.11-1.71)$ & 0.004 & $1.08(0.82-1.40)$ & 0.59 \\
\hline \multicolumn{7}{|l|}{ Attitude towards sexual health } \\
\hline 3 correct & 231 & 31.2 & 1 & & 1 & \\
\hline $0-2$ correct & 1510 & 45.5 & $1.91(1.41-2.58)$ & $<0.001$ & $1.36(0.89-2.09)$ & 0.16 \\
\hline
\end{tabular}

*Adjusted for age, education, time slept away in the past year and knowledge of where to access condoms in the village.

$\mathrm{Cl}$, confidence interval; OR, odds ratio; STI, sexually transmitted infection. 
Table 10 Association of reported sexual behaviours and contraceptive use with pregnancy in sexually active, never-married women

\begin{tabular}{|c|c|c|c|c|c|c|}
\hline $\begin{array}{l}\text { Reported sexual behaviours and contraceptive } \\
\text { use }\end{array}$ & $\begin{array}{l}\text { Women } \\
(n)\end{array}$ & $\begin{array}{l}\text { Pregnancy } \\
(\%)\end{array}$ & $\begin{array}{l}\text { Crude OR } \\
(95 \% \mathrm{CI})\end{array}$ & $p$ & $\begin{array}{l}\text { Adjusted OR } \\
(95 \% \mathrm{Cl})^{*}\end{array}$ & $p$ \\
\hline \multicolumn{7}{|l|}{ Age at first sex (years) } \\
\hline$\geq 16$ & 1273 & 42.7 & 1 & & 1 & \\
\hline$<16$ & 463 & 46.7 & $1.15 \quad(0.93-1.44)$ & 0.20 & $0.98 \quad(0.75-1.30)$ & 0.91 \\
\hline \multicolumn{7}{|l|}{ Lifetime number of partners $(n)$} \\
\hline 1 & 750 & 24.8 & 1 & & 1 & \\
\hline $2-4$ & 851 & 55.0 & $3.62(2.91-4.50)$ & & $2.87 \quad(2.21-3.73)$ & \\
\hline$\geq 5$ & 141 & 75.2 & $9.24(6.05-14.11)$ & $<0.001$ & $6.83(4.15-11.24)$ & $<0.001$ \\
\hline \multicolumn{7}{|l|}{ Ever used modern contraceptive to prevent pregnancy } \\
\hline Yes & 1138 & 37.2 & 1 & & 1 & \\
\hline No & 604 & 55.8 & $2.00 \quad(1.63-2.46)$ & $<0.001$ & $1.62 \quad(1.21-2.19)$ & 0.001 \\
\hline \multicolumn{7}{|l|}{ Casual partner in the past year } \\
\hline No & 1243 & 43.8 & 1 & & 1 & \\
\hline Yes & 497 & 43.3 & $0.98 \quad(0.79-1.21)$ & 0.56 & $0.56 \quad(0.42-0.73)$ & $<0.001$ \\
\hline \multicolumn{7}{|l|}{ Regular partner in the past year } \\
\hline No & 634 & 39.8 & 1 & & 1 & \\
\hline Yes & 1106 & 45.8 & $1.23(1.01-1.51)$ & 0.04 & $0.86(0.65-1.15)$ & 0.31 \\
\hline
\end{tabular}

${ }^{*}$ Adjusted for age group, educational level, time slept away in the past year, access to condoms in the village, lifetime number of partners, use of modern contraceptives to prevent pregnancy and having had a casual partner in the past year.

$\mathrm{Cl}$, confidence interval; OR, odds ratio.

Given the results of this study, several recommendations, spanning both policy and research, can be made. With respect to research, it is important to establish a better way of measuring unplanned pregnancies. In particular, it would be useful to try to tease out unwanted pregnancies from those that were mistimed but ultimately welcomed by the woman. With the very high prevalence of pregnancy it would be possible to conduct a cohort study that would partially overcome temporality issues and would prevent the birth of the child affecting the woman's view as to whether the pregnancy was planned or unplanned in the analysis. In particular, given the tradition in Mwanza region of girls leaving school when they become pregnant, ${ }^{24}$ it would be interesting to explore longitudinally the relationship between educational level and pregnancy outside marriage.

The results from this study also have practical implications for the design of interventions and policy. Intensified efforts are needed to promote the use of modern contraceptives in rural areas of Tanzania, and to encourage a reduction in the number of sexual partners. In our study, most women who reported using modern contraceptives used condoms, with much lower percentages using injectable contraceptives or the contraceptive pill. This pattern was particularly notable amongst the never-married women, although hormonal contraception was available at the health facilities. Ethnographic work carried out in the Mwanza region of Tanzania found that women were unlikely to use oral contraceptives due to the belief that they would damage long-term fertility. ${ }^{9}$ This highlights the importance of both ensuring the availability of modern contraceptives and correcting misinformation. Furthermore, whilst this study focused only on women, it is important to also ensure that men are educated on the importance of contraceptive use to prevent unplanned pregnancies as it has repeatedly been found in qualitative studies that partners' attitudes towards contraception affect modern contraceptive use amongst young women. ${ }^{5}$ This is particularly important for areas with high HIV prevalence as condoms not only protect against pregnancy but also HIV transmission. Finally, it is evident from our results that it is of great importance to encourage women to stay in school, not only to provide them with the skills and knowledge with which to avoid pregnancy should they want to, but to increase their aspirations for the future, providing them with a motivation to avoid pregnancy.

\section{Author affiliations}

${ }^{1}$ Research Degree Student, Department of Infectious Disease Epidemiology, London School of Hygiene and Tropical Medicine, London, UK

${ }^{2}$ Lecturer, Department of Infectious Disease Epidemiology, London School of Hygiene and Tropical Medicine, London, UK; National Institute for Medical Research, Mwanza Centre, Mwanza, Tanzania; and Mwanza Intervention Trials Unit, Mwanza, Tanzania

${ }^{3}$ Lecturer, Department of Infectious Disease Epidemiology, London School of Hygiene and Tropical Medicine, London, UK; National Institute for Medical Research, Mwanza Centre, Mwanza, Tanzania; and Mwanza Intervention Trials Unit, Mwanza, Tanzania

${ }^{4}$ Districts Coordinator, Mwanza Intervention Trials Unit, Mwanza, Tanzania 
${ }^{5}$ Director of National Institute for Medical Research (NIMR) Mwanza, National Institute for Medical Research, Mwanza Centre, Mwanza, Tanzania ${ }^{6}$ Reader, National Institute for Medical Research, Mwanza Centre, Mwanza, Tanzania; Mwanza Intervention Trials Unit, Mwanza, Tanzania; and Department of Clinical Research, London School of Hygiene and Tropical Medicine, London, UK ${ }^{7}$ Professor, Department of Infectious Disease Epidemiology, London School of Hygiene and Tropical Medicine, London, UK

${ }^{8}$ Professor, Department of Infectious Disease Epidemiology, London School of Hygiene and Tropical Medicine, London, UK

Acknowledgements The authors would like to thank all the participants, intervention, survey, data, laboratory, social science and administrative staff in London and Mwanza for both the first and second phase of the MEMA kwa Vijana trial. Additionally they thank the trial's steering, scientific advisory, and data and safety monitoring committees. The authors also thank the Tanzanian Ministries of Health and of Education, National AIDS Control Programme, and Medical Research Co-ordinating Committee, and the Ethics Committee of the LSHTM, for permission to carry out and publish the results of this study. They are also grateful to the Regional Medical and Education Officers of Mwanza and the National Directors of NIMR and AMREF for their support.

Funding This study was funded through grants from the European Commission, the UK Department for International Development and Irish Aid. Additional funding was received from the Medical Research Council of Great Britain and the United Nations Joint Programme on HIV/AIDS (UNAIDS).

\section{Competing interests None.}

Ethics approval The trial protocol received ethical and research clearance from the Tanzanian Medical Research Coordinating Committee and the London School of Hygiene and Tropical Medicine Ethics Committee.

Provenance and peer review Not commissioned; externally peer reviewed.

Open Access This is an Open Access article distributed in accordance with the Creative Commons Attribution Non Commercial (CC BY-NC 3.0) license, which permits others to distribute, remix, adapt, build upon this work non-commercially, and license their derivative works on different terms, provided the original work is properly cited and the use is non-commercial. See: http://creativecommons.org/licenses/by-nc/3.0/

\section{REFERENCES}

1 World Health Organization. Making Pregnancy Safer: Annual Report 2007. Geneva, Switzerland: World Health Organization, 2008.

2 Oringange C, Meremikwu MM, Eko H, et al. Interventions for preventing unintended pregnancies among adolescents. Cochrane Database Syst Rev 2009;4:CD005215.

3 Darroch JE, Singh S, Nadeau J. Contraception: An Investment in Lives, Health and Development. In Brief (No. 5). New York, NY: Guttmacher Institute and United Nations Population Fund, 2008.

4 The United Republic of Tanzania: Statistics. http://www.unicef.org/ infobycountry/tanzania_statistics.html [accessed 10 May 2013].

5 Williamson L, Parkes A, Wight D, et al. Limits to modern contraceptive use among young women in developing countries: a systematic review of qualitative research. Reprod Health 2009;6:3.

6 Hubacher D, Mavranezouli I, McGinn E. Unintended pregnancy in sub-Saharan Africa: magnitude of the problem and potential role of contraceptive implants to alleviate it. Contraception 2008;78:73-78.

7 Blum RW. Youth in Sub-Saharan Africa. J Adolesc Health 2007;41:230-238.

8 World Health Organization. Why is Giving Special Attention to Adolescents Important for Achieving Millennium Development Goal 5? Geneva, Switzerland: World Health Organization, 2008.

9 Plummer ML, Wamoyi J, Shigongo Z, et al. 'Seek any means, and keep it your secret': young women's attempts to control their reproduction through contraceptive and fertility practices in rural Tanzania. Tanzanian J Health Res 2010;12:178-193.

10 Plummer M, Wamoyi J, Nyalali K, et al. Aborting and suspending pregnancy in rural Tanzania: an ethnography of young people's beliefs and practices. Stud Fam Plann 2008;39:281-292.

11 Jewkes R, Nduna M, Levin J, et al. Impact of stepping stones on incidence of HIV and HSV-2 and sexual behaviour in rural South Africa: cluster randomised controlled trial. BMJ 2008;337: a506.

12 Ross DA, Changalucha J, Obasi AI, et al. Biological and behavioural impact of an adolescent sexual health intervention in Tanzania: a community-randomized trial. AIDS 2007;21:1943-1955.

13 Doyle AM, Ross DA, Maganja K, et al. Long-term biological and behavioural impact of an adolescent sexual health intervention in Tanzania: follow-up survey of the community-based MEMA kwa Vijana Trial. PLoS Med 2010;7:e1000287.

14 Cowan FM, Pascoe SJ, Langhaug LF, et al. The Regai Dzive Shiri project: results of a randomized trial of an HIV prevention intervention for youth. AIDS 2010;24:2541-2552.

15 Hayes RJ, Changalucha J, Ross DA, et al. The MEMA kwa Vijana Project: design of a community randomised trial of an innovative adolescent sexual health intervention in rural Tanzania. Contemp Clin Trials 2005;26:430-442.

16 Obasi AI, Cleophas B, Ross DA, et al. Rationale and design of the MEMA kwa Vijana adolescent sexual and reproductive health intervention in Mwanza Region, Tanzania. Aids Care 2006; 18:311-322.

17 Victora CG, Huttly SR, Fuchs SC, et al. The role of conceptual frameworks in epidemiological analysis: a hierarchical approach. Int J Epidemiol 1997;26:224-227.

18 Sedgh G, Bankole A, Oye-Adeniran B, et al. Unwanted pregnancy and associated factors among Nigerian women. Int Fam Plan Perspec 2006;32:175-184.

19 Kuroki LM, Allsworth JE, Redding CA, et al. Is a previous unplanned pregnancy a risk factor for a subsequent unplanned pregnancy? Am J Obstet Gynecol 2008;199:e511-e517.

20 Santelli J, Rochat R, Hatfield-Timajchy K, et al. The measurement and meaning of unintended pregnancy. Perspect Sex Reprod Health 2003;35:94-101.

21 Mbizvo MT, Bonduelle MMJ, Chadzuka S, et al. Unplanned pregnancies in Harare: what are the social and sexual determinants? Soc Sci Med 1997;45:937-942.

22 Finer L, Henshaw S. Disparities in rates of unintended pregnancy in the United States, 1994 and 2001. Perspect Sex Reprod Health 2006;38:90-96.

23 Tsui AO, McDonald-Mosley R, Burke AE. Family planning and the burden of unintended pregnancies. Epidemiol Rev 2010;32:152-174.

24 Plummer ML, Wight D. Young People's Lives and Sexual Relationships in Rural Africa. Washington, DC: Lexington Books, 2011. 